\title{
CDISC SEND Severity Terminology
}

National Cancer Institute

\section{Source}

National Cancer Institute. CDISC SEND Severity Terminology. NCI Thesaurus. Code C90000.

The terminology that includes concepts relevant to the Clinical Data Interchange Standards Consortium (CDISC) Standard for the Exchange of Non-clinical Data (SEND) severity. 